\title{
The global survival rate among adult out-of-hospital cardiac arrest patients who received cardiopulmonary resuscitation: a systematic review and meta-analysis
}

\author{
Shijiao Yan ${ }^{1,2 \dagger}$, Yong Gan ${ }^{3 \dagger}$, Nan Jiang ${ }^{3}$, Rixing Wang ${ }^{4}$, Yunqiang Chen ${ }^{5,2}$, Zhiqian Luo ${ }^{5,2}$, Qiao Zong ${ }^{6}$,
} Song Chen ${ }^{7}$ and Chuanzhu Lv $\mathrm{Lv}^{4,5,2^{*}}$

\begin{abstract}
Background: To quantitatively summarize the available epidemiological evidence on the survival rate of out-ofhospital cardiac arrest (OHCA) patients who received cardiopulmonary resuscitation (CPR).

Methods: We systematically searched the PubMed, Embase, and Web of Science databases, and the references of retrieved articles were manually reviewed to identify studies reporting the outcome of OHCA patients who received CPR. The overall incidence and outcome of OHCA were assessed using a random-effects meta-analysis.

Results: A total of 141 eligible studies were included in this meta-analysis. The pooled incidence of return of spontaneous circulation (ROSC) was $29.7 \%$ (95\% Cl 27.6-31.7\%), the rate of survival to hospital admission was $22.0 \%$ (95\% Cl 20.7-23.4\%), the rate of survival to hospital discharge was 8.8\% (95\% Cl 8.2-9.4\%), the pooled 1-month survival rate was 10.7\% (95\% Cl 9.1-13.3\%), and the 1-year survival rate was 7.7\% (95\% Cl 5.8-9.5\%). Subgroup analysis showed that survival to hospital discharge was more likely among OHCA patients whose cardiac arrest was witnessed by a bystander or emergency medical services (EMS) (10.5\%; 95\% Cl 9.2-11.7\%), who received bystander CPR (11.3\%, 95\% Cl 9.3-13.2\%), and who were living in Europe and North America (Europe 11.7\%; 95\% Cl 10.513.0\%; North America: 7.7\%; 95\% Cl 6.9-8.6\%). The survival to discharge (8.6\% in 1976-1999 vs. 9.9\% in 2010-2019), 1 -month survival (8.0\% in 2000-2009 vs. $13.3 \%$ in 2010-2019), and 1-year survival (8.0\% in 2000-2009 vs. $13.3 \%$ in 2010-2019) rates of OHCA patients who underwent CPR significantly increased throughout the study period. The Egger's test did not indicate evidence of publication bias for the outcomes of OHCA patients who underwent CPR. Conclusions: The global survival rate of OHCA patients who received CPR has increased in the past 40 years. A higher survival rate post-OHCA is more likely among patients who receive bystander CPR and who live in Western countries.
\end{abstract}

Keywords: Out-of-hospital cardiac arrest, Resuscitation, Emergency medical services

\section{Background}

Out-of-hospital cardiac arrest (OHCA) is a major public health challenge, with an average global incidence among adults of 55 OHCAs per 100,000 person-years. [1] In China,

\footnotetext{
* Correspondence: Ivchuanzhu677@126.com

t'Shijiao Yan and Yong Gan contributed equally to this work.

${ }^{4}$ Department of Emergency, Hainan Clinical Research Center for Acute and Critical Diseases, The Second Affiliated Hospital of Hainan Medical University, Haikou, Hainan, China

${ }^{5}$ Emergency and Trauma College, Hainan Medical University, Haikou, Hainan, China

Full list of author information is available at the end of the article
}

there are more than 230 million people with cardiovascular disease, and 550,000 individuals experience cardiac arrest every year [2]. Worldwide, survival after OHCA remains poor [3]. In China, the survival rate of OHCA is less than $1 \%$ [4]. Early initiation, good cardiopulmonary resuscitation (CPR) quality, and the use of an automated external defibrillator (AED) significantly improved survival and long-term outcomes in survivors of OHCA [2, 5-7].

Many studies have been conducted to estimate the survival rate among OHCA patients who received CPR in different regions of the world $[4,8-13]$. However, the

(c) The Author(s). 2020 Open Access This article is distributed under the terms of the Creative Commons Attribution 4.0 International License (http://creativecommons.org/licenses/by/4.0/), which permits unrestricted use, distribution, and 
results were inconsistent across studies. The purpose of this systematic review and meta-analysis was to estimate the overall incidence of the return of spontaneous circulation (ROSC), the survival to admission rate, the survival to discharge rate, the 1-month survival rate, and the 1-year survival rate of patients after OHCA who received CPR worldwide.

\section{Methods}

This systematic review and meta-analysis adhered to the Preferred Reporting Items for Systematic Reviews and Meta-Analyses (PRISMA) guidelines [14] and the Metaanalysis of Observational Studies in Epidemiology (MOOSE) checklist [15].

\section{Search strategy}

Studies that reported survival rates among OHCA patients who underwent CPR were identified from the PubMed, Embase, and Web of Science databases from their inception to February 2019. The search terms were "out-of-hospital cardiac arrest" or "out-of-hospital ventricular fibrillation/ventricular tachycardia/ asystole/pulseless electrical activity" or "cardiopulmonary resuscitation" or "CPR" or "mouth to mouth" or "resuscitation" or "resuscitation orders" or "survival" or "survival rate" or "mortality" or "sudden cardiac death". Only articles published in English were considered. Additionally, we manually reviewed the references listed in the retrieved articles to identify additional pertinent publications.

\section{Inclusion criteria and exclusion criteria}

Studies were included if they met the following eligibility criteria: (1) the study design was based on the Utsteinstyle reporting guidelines; (2) the study population was composed of adults, which included any study in which less than $20 \%$ of study population were pediatric patients (age < 18 years); (3) the outcome variables were at least one of the following: ROSC, survival to admission rate, survival to hospital discharge rate, 1-month survival rate, and 1-year survival rate; (4) cardiac arrest happened outside the hospital; and (5) the study design was prospective, retrospective, or interventional. Reviews, letters, editorials, guidelines, and case reports were excluded. When multiple publications were produced using the same study population, the most recent and informative paper was included.

\section{Data extraction}

Two independent reviewers (YG and NJ) performed the data extraction. The following data were extracted from the studies: the first author's name, region of population, year of publication, sex, number of cardiac arrests and survivors, cardiac arrest witness type, provision of CPR, and origin of cardiac arrest. The rate of survival to hospital discharge was considered the primary outcome; ROSC, the rate of survival to hospital admission, 1-month survival rate and 1-year survival rate were also analyzed as outcome variables. Any disagreements between the investigators were discussed, and an agreement was reached through consensus.

\section{Statistical analysis}

A random-effects model was used to estimate the survival rates among OHCA patients who received CPR [16]. Studies that reported the survival outcomes of OHCA patients who received CPR (ROSC, survival to admission rate, survival to discharge rate, 1-month survival rate, and 1-year survival rate) were treated as independent reports.

Statistical heterogeneity across studies was assessed with the $I^{2}$ statistic, where values of $25 \%, 50 \%$, and $75 \%$ represented the cut-off points for low, moderate, and high levels of heterogeneity, respectively [17]. Publication bias was evaluated with funnel plots and Egger's test [18]. Subgroup analyses stratified by sex, study location, study period, origin of OHCA, CPR type, and cardiac arrest witness type were conducted to investigate potential sources of heterogeneity across subgroups and examine the robustness of the primary results. We performed sensitivity analyses by omitting one study at a time to assess the influence of any single study on the pooled survival rate estimates. All statistical analyses were conducted with STATA V.12.0 (StataCorp, College Station, TX). All tests were two-tailed with a significance level of 0.05 .

\section{Results}

\section{Study selection}

The process of study selection, identification, and inclusion using the Preferred Reporting Items for Systematic Reviews and Meta-Analyses flow diagram is presented in Fig. 1. Initially, 5502 articles were retrieved from the PubMed, Embase, and Web of Science databases. In addition, we identified 13 articles by manually searching the reference lists of the retrieved articles. After removing 915 duplicate articles, we further excluded 4371 articles based on the titles and abstracts, including 336 nonhuman studies and 280 reviews, editorials, letters, guidelines or case reports. A total of 229 articles were selected for further full texts assessment. After retrieving the full-text for evaluation in detail, 88 articles were excluded because their study populations were pediatric patients, their primary outcome focused on the neurological survival rate or they were multiple publications produced using the same study population. Finally, a total of 141 studies were included in the present meta- 


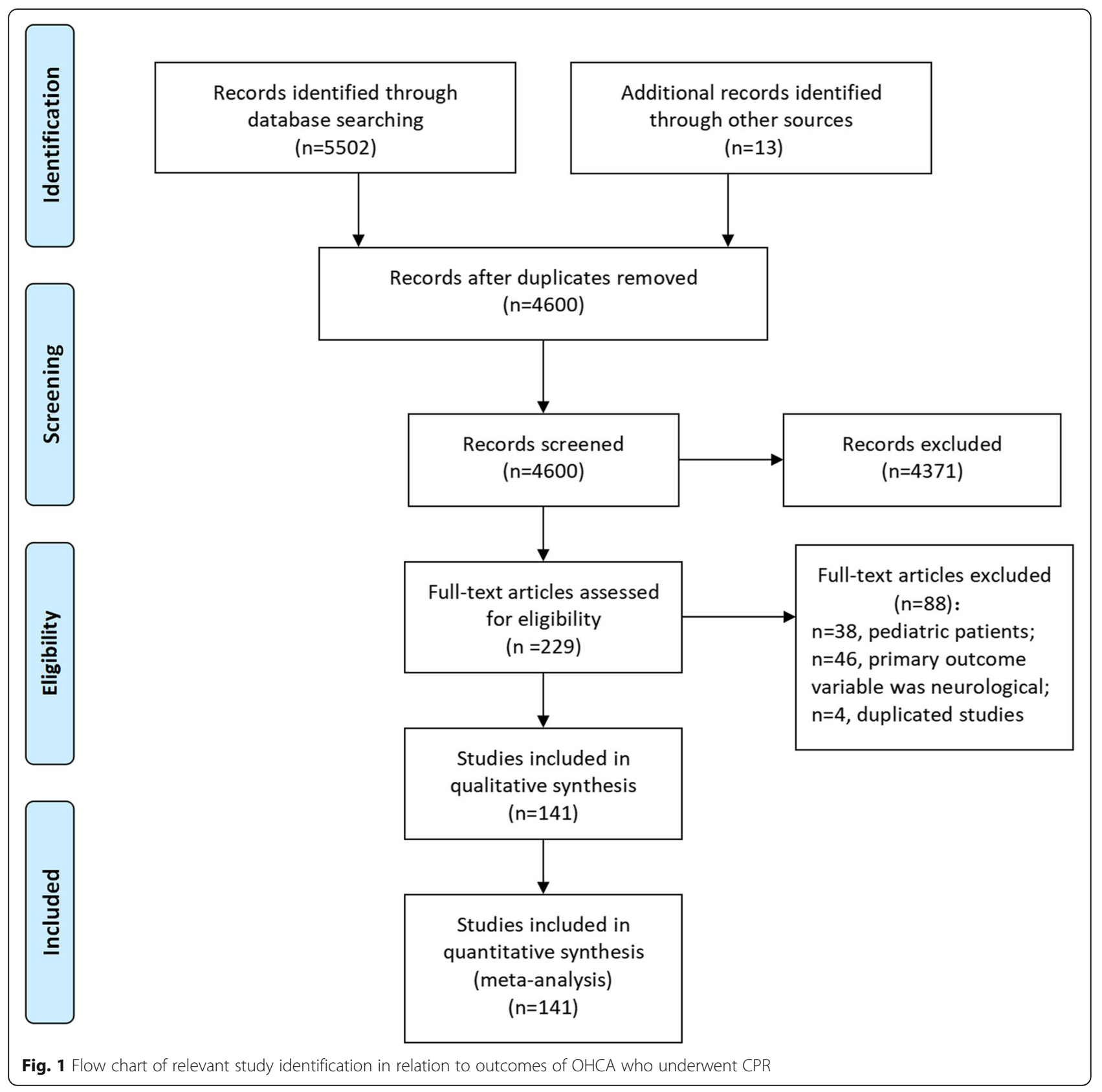

analysis. The references of the studies included in the meta-analysis are listed in the Additional file 1.

\section{Characteristics and quality of the studies included}

The characteristics of the 141 included studies are shown in Supplementary Table 1. These studies were conducted on 4 continents. Fifty-six studies were conducted in Europe, 48 in North America, 29 in Asia, 6 in Oceania, and two in both Europe and North America. A total of 31 studies reported the survivors and study population stratified by sex. The year of publication ranged from 1976 to 2019. In total, 4,610,669 OHCA patients who underwent CPR were involved in this study.
We included 62 studies that reported the incidence of ROSC, 88 studies that explored the rate of survival to admission, 103 studies that assessed the rate of survival to discharge, 33 studies that investigated the 1-month survival rate, and 22 studies that reported the 1-year survival rate. Nineteen studies included pediatric patients, but less than $20 \%$ of study population was younger than 18 years.

ROSC

In this study, 62 studies with 74 reports reported the outcome of ROSC in OHCA patients who underwent CPR. From the random-effects meta-analysis, we found 
that the pooled incidence of ROSC among OHCA patients was $29.7 \%$ (95\% CI, 27.6-31.7\%) with significant heterogeneity across studies $\left(I^{2}=99.9 \%, P<0.001\right)$.

Subgroup analyses showed significant differences in the incidence of prehospital ROSC by study location, the provider of CPR, and study period (Table 1). With regard to study location, Oceania had the highest incidence of ROSC (38.6\%; 95\% CI 22.9-54.2\%), followed by Europe (36.7\%; 95\% CI 32.4-40.9\%). Asia had the lowest incidence of ROSC (22.1\%; 95\% CI 18.1-26.0\%). Regarding the provider of CPR, the incidence of ROSC was the highest among OHCA patients who had received CPR from emergency medical services (EMS) (36.3\%; 95\% CI 23.8-48.9\%).

\section{Survival to admission}

A total of 88 studies with 122 reports estimated the incidence of survival to admission of OHCA patients who underwent CPR. From the random-effects meta-analysis, an incidence of $22.0 \%$ (95\% CI 20.7-23.4\%) for survival to admission was estimated globally among OHCA patients who received CPR.

With regard to study location, Oceania had the highest incidence (33.5\%; 95\% CI 21.7-45.3\%), followed by Europe (25.7\%; 95\% CI 23.9-27.6\%), North America (20.5\%; 95\% CI 18.1-22.9\%), and Asian countries (15.6\%; 95\% CI $13.2-18.0 \%)$.

\section{Survival to discharge}

One hundred and three studies with 168 reports investigated the rate of survival to discharge of OHCA patients who underwent CPR. From the random-effects metaanalysis, an incidence of $8.8 \%$ (95\% CI $8.2-9.4 \%$ ) for survival to discharge was estimated globally among OHCA patients, and there was high heterogeneity across studies $\left(P<0.001 ; I^{2}=97.6 \%\right)$ (Table 1$)$. The rate of survival to discharge of OHCA patients who received CPR increased from $8.6 \%$ (95\% CI 7.7-9.5\%) in 1976-1999 to 9.9\% (95\% CI 8.4-11.4\%) in 2010-2019.

Subgroup analyses showed significant differences in the survival rate by study location and provider of CPR. Across the study locations, Oceania had the highest survival rate (16.2\%; 95\% CI 5.9-26.5\%), followed by Europe (11.7\%; 95\% CI 10.5-13.0\%), North America (7.7\%; 95\% CI 6.9-8.6\%), and Asia (4.5\%; 95\% CI 3.1-5.9\%). Regarding the provider of $\mathrm{CPR}$, the survival rate was relatively higher among patients who received bystander CPR (11.3\%; 95\% CI 9.3-13.2\%).

\section{One-month survival rate}

In total, 33 studies with 54 reports investigated the 1 month survival rate of OHCA patients who underwent CPR. From the random-effects meta-analysis, an incidence of $10.7 \%$ (95\% CI 9.1-12.3\%) for 1-month survival was estimated globally among OHCA patients who had received $\mathrm{CPR}$, and there was high heterogeneity among the studies $\left(P<0.001 ; I^{2}=99.9 \%\right)$.

Subgroup analyses showed significant differences in 1-month survival by study location and study period. Across the study locations, Oceania had the highest survival rate $(16.0 \%$; $95 \%$ CI $8.4-23.7 \%)$, followed by Asia (12.8\%; 95\% CI 10.0-15.5\%), Europe (9.0\%; 95\% CI $7.6-10.3 \%$ ), and North America (6.5\%; 95\% CI $4.6-8.5 \%)$. Across the study periods, the 1 -month survival rate increased from $8.0 \%(95 \% \mathrm{CI}, 6.7-9.3 \%)$ in $2000-2009$ to $13.3 \%$ (95\% CI 10.9-15.7\%) in $2010-2019$.

\section{One-year survival rate}

Twenty-seven reports from 22 studies investigated the 1 year survival rate of OHCA patients who underwent CPR. From the random-effects meta-analysis, an incidence of $7.7 \%$ (95\% CI 5.8-9.5\%) for 1-year survival was estimated globally among OHCA patients who received CPR, and there was high heterogeneity among the studies $\left(P<0.001 ; I^{2}=97.5 \%\right)$.

Subgroup analyses showed significant differences in 1 -year survival by study location and study period. Across the study locations, Oceania had the highest survival rate (11.5\%; 95\% CI 10.0-13.0\%), followed by Europe (9.2\%; 95\% CI 6.4-12.0\%), Asia (5.3\%; 95\% CI 2.7-8.0\%), and North America (4.0\%; 95\% CI 2.8-5.3\%). Across the study periods, the 1-year survival rate increased from $6.0 \%$ (95\% CI $4.3-7.6 \%$ ) in $2000-2009$ to $12.3 \%$ (95\% CI $5.4-19.3 \%$ ) in 2010-2019. Regarding the provider of CPR, the survival rate was relatively higher among patients who received bystander CPR (12.3\%; 95\% CI 6.4-18.1\%).

\section{Sensitivity analyses}

The exclusion of studies with sample sizes less than 100 yielded pooled incidences of $29.0 \%$ (95\% CI 26.8-31.2\%, $P<0.001$ ), $21.6 \%$ (95\% CI 20.1-23.0\%, $P<0.001$ ), $8.6 \%$ (95\% CI 8.0-9.2\%, $P<0.001$ ), 10.8\% (95\% CI 9.2-12.4\%, $P<0.001$ ), and $7.6 \%$ (95\% CI 5.7-9.5\%, $P<0.001$ ) for ROSC, survival to hospital admission, survival to hospital discharge, 1-month survival, and 1-year survival, respectively. Thus, the survival rate did not change significantly when the observations with sample sizes less than 100 were excluded, which indicated that studies with small sample sizes did not influence the overall result. Furthermore, after the exclusion of these studies $(n=19)$ including pediatric patients, the pooled survival rates for ROSC, survival to hospital admission, survival to hospital discharge, 1-month survival, and 1-year survival were $30.5 \%$ (95\% CI 26.7-34.3\%, $P<0.001$ ), 21.8\% (95\% CI 20.4-23.3\%, $P<0.001$ ), 9.7\% (95\% CI 8.9-10.5\%, $P<0.001$ ), 10.1\% (95\% CI $7.9-12.3 \%, P<0.001$ ), and $7.6 \%$ (95\% CI 5.6-9.6\%, $P<0.001)$, respectively. 
Table 1 The incidence of ROSC, survival to admission, survival to discharge, 1 month survival, and 1 year survival: the overall estimates and subgroup analyses

\begin{tabular}{|c|c|c|c|c|c|c|c|}
\hline & No. of reports & Survivors & OHCA cases & Proportion (\%) & $95 \% \mathrm{Cl}$ & $P^{2}$ & $\begin{array}{l}P \text { value for } \\
\text { heterogeneity }\end{array}$ \\
\hline ROSC* & 74 & 203,084 & $1,560,830$ & 29.7 & 27.6 to 31.7 & $99.90 \%$ & $<0.001$ \\
\hline \multicolumn{8}{|l|}{ Sex } \\
\hline Men & 2 & 242 & 856 & 28.9 & 24.2 to 33.6 & $43.4 \%$ & 0.184 \\
\hline Women & 2 & 151 & 478 & 31.6 & 27.4 to 35.8 & $0.00 \%$ & 0.542 \\
\hline Combined & 70 & 202,691 & $1,559,496$ & 29.7 & 27.6 to 31.8 & $99.90 \%$ & $<0.001$ \\
\hline \multicolumn{8}{|l|}{ Study location } \\
\hline Europe & 32 & 4166 & 12,274 & 36.7 & 32.4 to 40.9 & $96.10 \%$ & $<0.001$ \\
\hline Asia & 17 & 186,060 & $1,500,110$ & 22.1 & 18.1 to 26.0 & $100.00 \%$ & $<0.001$ \\
\hline North America & 20 & 6981 & 32,520 & 24.3 & 19.7 to 28.9 & $99.10 \%$ & $<0.001$ \\
\hline Oceania & 5 & 5877 & 15,926 & 38.6 & 22.9 to 54.2 & $99.20 \%$ & $<0.001$ \\
\hline \multicolumn{8}{|l|}{ Study period } \\
\hline 1976-1999 & 25 & 3706 & 15,429 & 34.2 & 28.0 to 40.4 & $98.70 \%$ & $<0.001$ \\
\hline 2000-2009 & 30 & 4091 & 17,159 & 28.3 & 23.9 to 32.7 & $98.00 \%$ & $<0.001$ \\
\hline 2010-2019 & 19 & 195,287 & $1,528,242$ & 27.5 & 23.6 to 31.3 & $100.00 \%$ & $<0.001$ \\
\hline \multicolumn{8}{|l|}{ CPR type } \\
\hline Bystander CPR & 17 & 138,149 & 863,978 & 26.3 & 20.9 to 31.8 & $100.00 \%$ & $<0.001$ \\
\hline EMS CPR & 15 & 45,505 & 624,496 & 36.3 & 23.8 to 48.9 & $99.50 \%$ & $<0.001$ \\
\hline Unspecific CPR & 42 & 19,430 & 72,356 & 29.6 & 25.9 to 33.3 & $99.30 \%$ & $<0.001$ \\
\hline \multicolumn{8}{|l|}{ Origin of OHCA } \\
\hline Cardiac etiology & 49 & 30,531 & 143,831 & 33.9 & 30.1 to 37.7 & $99.50 \%$ & $<0.001$ \\
\hline Non-traumatic & 14 & 7652 & 33,318 & 21.5 & 16.2 to 26.8 & $99.20 \%$ & $<0.001$ \\
\hline All patients & 11 & 164,901 & $1,383,681$ & 23.3 & 18.3 to 28.3 & $100.00 \%$ & $<0.001$ \\
\hline Others & NA & NA & NA & NA & NA & NA & NA \\
\hline \multicolumn{8}{|l|}{ Witnessed type } \\
\hline Witnessed & 31 & 106,894 & 440,281 & 36.4 & 30.6 to 42.2 & $99.90 \%$ & $<0.001$ \\
\hline Not witnessed & 1 & 34 & 93 & 36.6 & 26.8 to 46.4 & $0.00 \%$ & $<0.001$ \\
\hline Mixed & 36 & 95,828 & $1,119,248$ & 23.7 & 22.2 to 25.3 & $99.80 \%$ & $<0.001$ \\
\hline Unspecific events & 6 & 328 & 1208 & 28.2 & 18.6 to 37.7 & $91.30 \%$ & $<0.001$ \\
\hline Survival to admission $\uparrow$ & 122 & 55,026 & 377,727 & 22.0 & 20.7 to 23.4 & $99.4 \%$ & $<0.001$ \\
\hline \multicolumn{8}{|l|}{ Sex } \\
\hline Men & 7 & 564 & 2829 & 20.3 & 16.3 to 24.3 & $81.00 \%$ & $<0.001$ \\
\hline Women & 7 & 254 & 1021 & 23.4 & 17.8 to 29.1 & $72.60 \%$ & $<0.001$ \\
\hline Combined & 108 & 54,208 & 373,877 & 22.1 & 20.6 to 23.5 & $99.40 \%$ & $<0.001$ \\
\hline \multicolumn{8}{|l|}{ Study location } \\
\hline Europe & 52 & 20,987 & 123,024 & 25.7 & 23.9 to 27.6 & $98.30 \%$ & $<0.001$ \\
\hline Asia & 27 & 23,551 & 203,283 & 15.6 & 13.2 to 18.0 & $99.70 \%$ & $<0.001$ \\
\hline North America & 39 & 5504 & 35,183 & 20.5 & 18.1 to 22.9 & $97.50 \%$ & $<0.001$ \\
\hline Oceania & 4 & 4984 & 16,237 & 33.5 & 21.7 to 45.3 & $98.90 \%$ & $<0.001$ \\
\hline \multicolumn{8}{|l|}{ Study period } \\
\hline 1976-1999 & 59 & 5704 & 33,083 & 22.4 & 20.0 to 24.8 & $97.30 \%$ & $<0.001$ \\
\hline 2000-2009 & 38 & 18,433 & 106,336 & 25.1 & 22.9 to 27.3 & $98.50 \%$ & $<0.001$ \\
\hline 2010-2019 & 25 & 30,889 & 238,308 & 17.2 & 14.4 to 19.9 & $99.80 \%$ & $<0.001$ \\
\hline
\end{tabular}


Table 1 The incidence of ROSC, survival to admission, survival to discharge, 1 month survival, and 1 year survival: the overall estimates and subgroup analyses (Continued)

\begin{tabular}{|c|c|c|c|c|c|c|c|}
\hline & No. of reports & Survivors & OHCA cases & Proportion (\%) & $95 \% \mathrm{Cl}$ & $P^{2}$ & $\begin{array}{l}P \text { value for } \\
\text { heterogeneity }\end{array}$ \\
\hline \multicolumn{8}{|l|}{ CPR type } \\
\hline Bystander CPR & 21 & 6660 & 44,028 & 22.8 & 18.8 to 26.8 & $99.10 \%$ & $<0.001$ \\
\hline EMS CPR & 23 & 2043 & 7657 & 25.5 & 19.7 to 31.2 & $97.40 \%$ & $<0.001$ \\
\hline Unspecific CPR & 78 & 46,323 & 326,042 & 21.1 & 19.5 to 22.7 & $99.50 \%$ & $<0.001$ \\
\hline \multicolumn{8}{|l|}{ Origin of $\mathrm{OHCA}$} \\
\hline Cardiac etiology & 66 & 22,682 & 143,612 & 23.5 & 21.2 to 25.9 & $99.50 \%$ & $<0.001$ \\
\hline Non-traumatic & 38 & 17,293 & 142,532 & 19.3 & 17.5 to 21.2 & $98.60 \%$ & $<0.001$ \\
\hline All patients & 11 & 13,953 & 86,443 & 20.4 & 17.1 to 23.7 & $99.10 \%$ & $<0.001$ \\
\hline Others & 7 & 1098 & 5140 & 23.6 & 19.4 to 27.7 & $91.50 \%$ & $<0.001$ \\
\hline \multicolumn{8}{|l|}{ Witnessed type } \\
\hline Witnessed & 37 & 12,027 & 88,992 & 23.2 & 20.3 to 26.1 & $99.60 \%$ & $<0.001$ \\
\hline Not witnessed & 1 & 23 & 93 & 24.7 & 15.9 to 33.5 & $0.00 \%$ & $<0.001$ \\
\hline Mixed & 75 & 42,630 & 286,470 & 21.6 & 20.1 to 23.1 & $99.10 \%$ & $<0.001$ \\
\hline Unspecific events & 9 & 346 & 2172 & 19.2 & 14.5 to 23.9 & $84.30 \%$ & $<0.001$ \\
\hline Survival to discharge ${ }^{\ddagger}$ & 168 & 20,946 & 267,862 & 8.8 & 8.2 to 9.4 & $97.60 \%$ & $<0.001$ \\
\hline \multicolumn{8}{|l|}{ Sex } \\
\hline Men & 22 & 1576 & 26,666 & 7.4 & 6.2 to 8.7 & $93.60 \%$ & $<0.001$ \\
\hline Women & 21 & 723 & 13,570 & 7.2 & 5.6 to 8.7 & $91.70 \%$ & $<0.001$ \\
\hline Combined & 125 & 18,647 & 227,626 & 9.3 & 8.5 to 10.0 & $97.90 \%$ & $<0.001$ \\
\hline \multicolumn{8}{|l|}{ Study location } \\
\hline Europe & 59 & 3607 & 33,673 & 11.7 & 10.5 to 13.0 & $92.70 \%$ & $<0.001$ \\
\hline Asia & 16 & 5329 & 86,333 & 4.5 & 3.1 to 5.9 & $98.60 \%$ & $<0.001$ \\
\hline North America & 89 & 10,115 & 131,564 & 7.7 & 6.9 to 8.6 & $97.60 \%$ & $<0.001$ \\
\hline Oceania & 4 & 1895 & 16,292 & 16.2 & 5.9 to 26.5 & $99.10 \%$ & $<0.001$ \\
\hline \multicolumn{8}{|l|}{ Study period } \\
\hline 1976-1999 & 80 & 4851 & 59,816 & 8.6 & 7.7 to 9.5 & $95.00 \%$ & $<0.001$ \\
\hline 2000-2009 & 63 & 5612 & 78,018 & 8.6 & 7.5 to 9.6 & $97.20 \%$ & $<0.001$ \\
\hline 2010-2019 & 25 & 10,483 & 130,028 & 9.9 & 8.4 to 11.4 & $99.10 \%$ & $<0.001$ \\
\hline \multicolumn{8}{|l|}{ CPR type } \\
\hline Bystander CPR & 35 & 4493 & 39,974 & 11.3 & 9.3 to 13.2 & $97.40 \%$ & $<0.001$ \\
\hline EMS CPR & 27 & 1754 & 14,108 & 10.7 & 8.2 to 13.2 & $95.80 \%$ & $<0.001$ \\
\hline Unspecific CPR & 106 & 14,699 & 213,780 & 7.7 & 7.0 to 8.3 & $97.40 \%$ & $<0.001$ \\
\hline \multicolumn{8}{|l|}{ Origin of OHCA } \\
\hline Cardiac etiology & 84 & 11,765 & 132,292 & 10.0 & 9.1 to 10.9 & $97.00 \%$ & $<0.001$ \\
\hline Non-traumatic & 62 & 7117 & 111,171 & 7.0 & 6.2 to 7.9 & $97.70 \%$ & $<0.001$ \\
\hline All patients & 13 & 879 & 9826 & 8.3 & 5.4 to 11.2 & $96.00 \%$ & $<0.001$ \\
\hline Others & 9 & 1185 & 14,573 & 10.1 & 8.3 to 12.0 & $89.50 \%$ & $<0.001$ \\
\hline \multicolumn{8}{|l|}{ Witnessed type } \\
\hline Witnessed & 44 & 8967 & 97,069 & 10.5 & 9.2 to 11.7 & $97.60 \%$ & $<0.001$ \\
\hline Not witnessed & 3 & 16 & 324 & 4.4 & 1.4 to 7.4 & $40.00 \%$ & 0.189 \\
\hline Mixed & 118 & 11,951 & 170,341 & 8.2 & 7.5 to 8.9 & $97.20 \%$ & $<0.001$ \\
\hline Unspecific events & 3 & 12 & 128 & 8.9 & 4.0 to 13.8 & $0.00 \%$ & 0.705 \\
\hline
\end{tabular}


Table 1 The incidence of ROSC, survival to admission, survival to discharge, 1 month survival, and 1 year survival: the overall estimates and subgroup analyses (Continued)

\begin{tabular}{|c|c|c|c|c|c|c|c|}
\hline & No. of reports & Survivors & OHCA cases & Proportion (\%) & $95 \% \mathrm{Cl}$ & $P^{2}$ & $\begin{array}{l}P \text { value for } \\
\text { heterogeneity }\end{array}$ \\
\hline One-month survival $^{\S}$ & 54 & 247,999 & $2,362,223$ & 10.7 & 9.1 to 12.3 & $99.9 \%$ & $<0.001$ \\
\hline \multicolumn{8}{|l|}{ Sex } \\
\hline Men & 4 & 3968 & 46,831 & 8.0 & 5.2 to 10.9 & $99.10 \%$ & $<0.001$ \\
\hline Women & 4 & 2477 & 18,891 & 9.5 & 3.2 to 15.8 & $99.50 \%$ & $<0.001$ \\
\hline Combined & 45 & 241,554 & $2,296,501$ & 11.0 & 9.3 to 12.8 & $100 \%$ & $<0.001$ \\
\hline \multicolumn{8}{|l|}{ Study location } \\
\hline Europe & 28 & 25,371 & 292,473 & 9.0 & 7.6 to 10.3 & $99.50 \%$ & $<0.001$ \\
\hline Asia & 21 & 222,285 & $2,066,705$ & 12.8 & 10.0 to 15.5 & $100 \%$ & $<0.001$ \\
\hline North America & 2 & 41 & 623 & 6.5 & 4.6 to 8.5 & $0.00 \%$ & 0.415 \\
\hline Oceania & 3 & 302 & 2422 & 16.0 & 8.4 to 23.7 & $96.10 \%$ & $<0.001$ \\
\hline \multicolumn{8}{|l|}{ Study period } \\
\hline 1976-1999 & NA & NA & NA & NA & NA & NA & NA \\
\hline 2000-2009 & 28 & 17,304 & 219,965 & 8.0 & 6.7 to 9.3 & $99.3 \%$ & $<0.001$ \\
\hline 2010-2019 & 26 & 230,695 & $2,142,258$ & 13.3 & 10.9 to 15.7 & $100 \%$ & $<0.001$ \\
\hline \multicolumn{8}{|l|}{ CPR type } \\
\hline Bystander CPR & 25 & 161,386 & $1,074,767$ & 12.8 & 9.0 to 16.7 & $100 \%$ & $<0.001$ \\
\hline EMS CPR & 6 & 37,308 & 666,669 & 12.3 & 8.6 to 16.0 & $99.70 \%$ & $<0.001$ \\
\hline Unspecific CPR & 23 & 49,305 & 620,787 & 7.9 & 7.1 to 8.7 & $99.20 \%$ & $<0.001$ \\
\hline \multicolumn{8}{|l|}{ Origin of OHCA } \\
\hline Cardiac etiology & 26 & 21,262 & 208,631 & 10.5 & 9.1 to 12.0 & $99.10 \%$ & $<0.001$ \\
\hline Non-traumatic & 1 & 23 & 342 & 6.7 & 4.1 to 9.3 & 0 & $<0.001$ \\
\hline All patients & 27 & 226,714 & $2,153,250$ & 10.8 & 8.5 to 13.1 & $100 \%$ & $<0.001$ \\
\hline Others & NA & NA & NA & NA & NA & NA & NA \\
\hline \multicolumn{8}{|l|}{ Witnessed type } \\
\hline Witnessed & 27 & 169,542 & $1,055,935$ & 13.2 & 10.3 to 16.1 & $99.9 \%$ & $<0.001$ \\
\hline Not witnessed & NA & NA & NA & NA & NA & NA & NA \\
\hline Mixed & 27 & 78,457 & $1,306,288$ & 8.3 & 7.4 to 9.1 & $99.7 \%$ & $<0.001$ \\
\hline Unspecific events & NA & NA & NA & NA & NA & NA & NA \\
\hline One-year survivalף & 27 & 3791 & 42,027 & 7.7 & 5.8 to 9.5 & $97.5 \%$ & $<0.001$ \\
\hline \multicolumn{8}{|l|}{ Sex } \\
\hline Men & 1 & 13 & 320 & 4.1 & 1.9 to 6.3 & $0.00 \%$ & $<0.001$ \\
\hline Women & 1 & 14 & 219 & 6.4 & 3.2 to 9.6 & $0.00 \%$ & $<0.001$ \\
\hline Combined & 25 & 3764 & 41,488 & 7.9 & 5.9 to 9.8 & $97.7 \%$ & $<0.001$ \\
\hline \multicolumn{8}{|l|}{ Study location } \\
\hline Europe & 16 & 3378 & 35,604 & 9.2 & 6.4 to 12.0 & $98.2 \%$ & $<0.001$ \\
\hline Asia & 3 & 118 & 2504 & 5.3 & 2.7 to 8.0 & $87.8 \%$ & $<0.001$ \\
\hline North America & 7 & 96 & 2190 & 4.0 & 2.8 to 5.3 & $51.2 \%$ & 0.056 \\
\hline Oceania & 1 & 199 & 1729 & 11.5 & 10.0 to 13.0 & $0.0 \%$ & $<0.001$ \\
\hline \multicolumn{8}{|l|}{ Study period } \\
\hline 1976-1999 & 10 & 407 & 3517 & 8.5 & 4.1 to 12.8 & $96.6 \%$ & $<0.001$ \\
\hline 2000-2009 & 14 & 479 & 7496 & 6.0 & 4.3 to 7.6 & $89.0 \%$ & $<0.001$ \\
\hline 2010-2019 & 3 & 2905 & 31,014 & 12.3 & 5.4 to 19.3 & $99.6 \%$ & $<0.001$ \\
\hline
\end{tabular}


Table 1 The incidence of ROSC, survival to admission, survival to discharge, 1 month survival, and 1 year survival: the overall estimates and subgroup analyses (Continued)

\begin{tabular}{|c|c|c|c|c|c|c|c|}
\hline & No. of reports & Survivors & OHCA cases & Proportion (\%) & $95 \% \mathrm{Cl}$ & $p^{2}$ & $\begin{array}{l}P \text { value for } \\
\text { heterogeneity }\end{array}$ \\
\hline \multicolumn{8}{|l|}{ CPR type } \\
\hline Bystander CPR & 2 & 1579 & 10,805 & 12.3 & 6.4 to 18.1 & $79.6 \%$ & 0.027 \\
\hline EMS CPR & 3 & 17 & 480 & 3.2 & 0.5 to 6.0 & $64.6 \%$ & 0.059 \\
\hline Unspecific CPR & 22 & 2195 & 30,742 & 7.6 & 6.1 to 9.2 & $95.2 \%$ & $<0.001$ \\
\hline \multicolumn{8}{|l|}{ Origin of OHCA } \\
\hline Cardiac etiology & 25 & 3763 & 41,493 & 7.9 & 6.0 to 9.9 & $97.6 \%$ & $<0.001$ \\
\hline Non-traumatic & 1 & 24 & 338 & 7.1 & 4.4 to 9.8 & $0.0 \%$ & $<0.001$ \\
\hline All patients & NA & NA & NA & NA & NA & NA & NA \\
\hline Others & 1 & 4 & 196 & 2.0 & 0 to 4.0 & $0.0 \%$ & $<0.001$ \\
\hline \multicolumn{8}{|l|}{ Witnessed type } \\
\hline Witnessed & 12 & 283 & 5765 & 5.3 & 4.0 to 6.5 & $77.9 \%$ & $<0.001$ \\
\hline Not witnessed & NA & NA & NA & NA & NA & NA & NA \\
\hline Mixed & 15 & 3508 & 36,262 & 9.0 & 6.1 to 11.9 & $98.3 \%$ & $<0.001$ \\
\hline Unspecific events & NA & NA & NA & NA & NA & NA & NA \\
\hline
\end{tabular}

Note: $\mathrm{Cl}$ confidence interval, $C P R$ cardiopulmonary resuscitation, EMS emergency medical services, NA not available, OHCA out-of-hospital cardiac arrests, $R O S C$ return of spontaneous circulation

*Two studies reported their results by study location, 2 studies reported their results by sex, 4 studies reported their results by CPR type, 2 studies reported their results by witness type, and 1 study reported their results by OHCA type; therefore, there were 74 reports from 62 studies

†Four studies reported their results by study location, 7 studies reported their results by sex, 7 studies reported their results by CPR type, 2 studies reported their results by witness type, and 1 study reported their results by OHCA type; therefore, there were 122 reports from 88 studies

${ }^{\text {F}}$ Three studies reported their results by study location, 21 studies reported their results by sex, 16 studies reported their results by CPR type, 1 study reported their results by witness type, and 2 studies reported their results by OHCA type; therefore, there were 168 reports from 103 studies

${ }^{\S}$ Four studies reported their results by sex, 4 studies reported their results by CPR type, 2 studies reported their results by OHCA type, and 1 study reported their results by year; therefore, there were 54 reports from 33 studies

१One study reported their results by sex, 2 studies reported their results by CPR type, and 1 study reported their results by witness type; therefore, there were 27 reports from 22 studies

Sensitivity analyses were performed by omitting each study in turn and combining the results of the remaining included studies. The overall summary survival rates for ROSC, survival to admission, survival to discharge, and the 1-month and 1-year survival rates did not alter substantially. The pooled survival rates derived from the sensitivity analyses for ROSC ranged from 28.8\% (95\% CI $27.5-30.1 \%$ ) to $30.3 \%$ (95\% CI $27.6-33.0 \%$ ), those for survival to hospital admission ranged from 21.7\% (95\% CI $20.4-23.1 \%$ ) to $22.2 \%$ (95\% CI $20.8-23.7 \%$ ), those for survival to hospital discharge ranged from $8.6 \%$ (95\% CI 8.0-9.2\%) to $8.9 \%$ (95\% CI 8.2-9.5\%), those for 1-month survival ranged from $10.1 \%$ (95\% CI $8.5-11.7 \%$ ) to $10.9 \%$ (95\% CI 9.3-12.4\%), and those for 1-year survival ranged from $6.9 \%$ (95\% CI 5.2-8.6\%) to $7.9 \%$ (95\% CI 6.0-9.8\%).

\section{Publication bias}

The funnel plot was symmetrical for the meta-analysis of the incidence of ROSC, survival to hospital admission, survival to hospital discharge, 1-month survival, and 1year survival in OHCA patients who received CPR (see Figs. 2, 3, 4, 5, and 6). The Egger's test revealed no evidence of publication bias among the studies that reported the incidence of ROSC, survival to admission, survival to hospital discharge, and 1-year survival rate (Egger's $P=0.362$ for ROSC; Egger's $P=0.128$ for survival to admission; Egger's $P=0.112$ for survival to hospital discharge; Egger's $P=0.168$ for 1-year survival). However, for the 1-month survival among OHCA patients who underwent CPR, we found that Egger's test revealed evidence of publication bias across studies (Egger's $P<0.05$ ).

\section{Discussion}

This is the first comprehensive systematic review and metaanalysis bringing together 40 years of research to estimate the incidence of ROSC, rate of survival to admission, rate of survival to discharge, 1-month survival rate, and 1-year survival rate among OHCA patients who received CPR worldwide. We found that the pooled incidence of ROSC, and survival to admission, survival to discharge, 1-month survival, and 1-year survival rates were $29.7 \%, 22.0 \%, 8.8 \%$, $10.7 \%$, and $7.7 \%$, respectively. In addition, much lower rates of the incidence of ROSC, survival to admission, and survival to discharge were observed across Asian countries and much higher survival to discharge, 1-month survival, and 1-year survival rates were found among OHCA patients who had received bystander CPR. Finally, survival to 


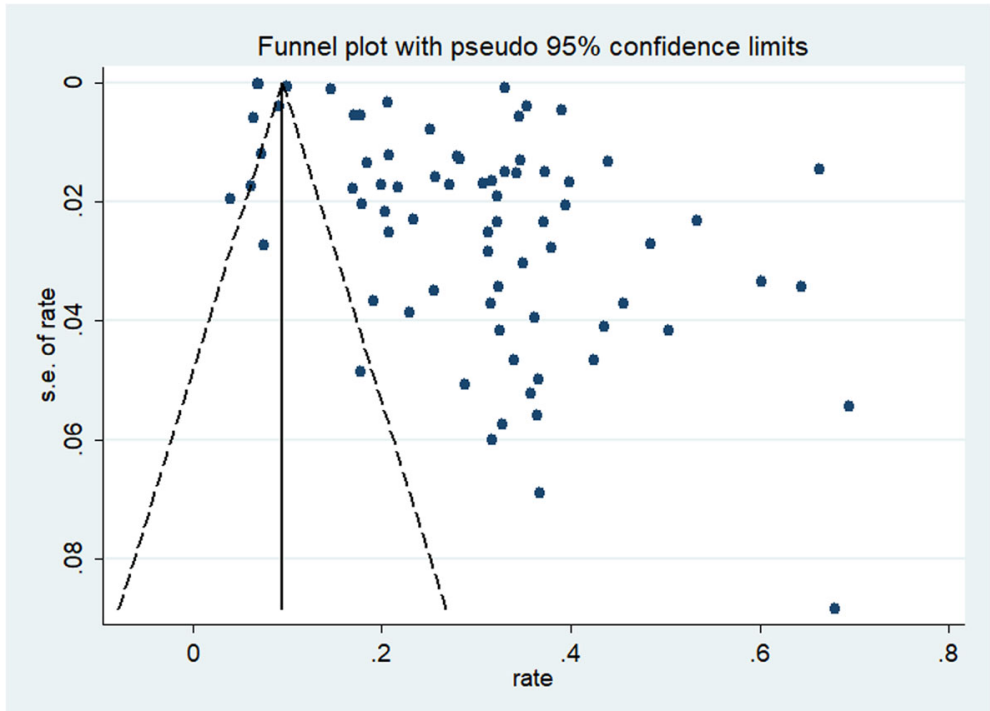

Fig. 2 Funnel plot for the incidence of ROSC among OHCA patients who underwent CPR

discharge among OHCA patients who underwent CPR significantly improved over the 40-year period.

Two previous studies published in 2010 [19] and 2013 [20] investigated the survival rate of OHCA patients who received CPR. The results of this current metaanalysis generally concur and further complement the findings of a previous review in several important aspects. Van de Glind et al. [20] reported that the pooled survival to discharge among patients $>70$ years of age was $4.1 \%$ (95\% CI 3.0-5.6\%), which was lower than that in the present study (8.8\%: $95 \%$ CI $8.2-9.4 \%$ ). One possible reason was that there were differences in the study population and sample size. The review by Van de Glind and colleagues included only 23 studies among older patients aged $>70$ years. However, our study population included all age groups. Several studies showed that increasing age was significantly associated with worse survival [21-23]. Additionally, their review did not fully investigate other subgroups or perform sensitivity analyses. Sasson et al. [19] found that the pooled survival to hospital discharge rate was 7.6\% (95\% CI 6.7-8.4\%). However, 62 studies were not included in their analysis because their search time was limited to 2008, which may have led to overestimation of the survival rate. In

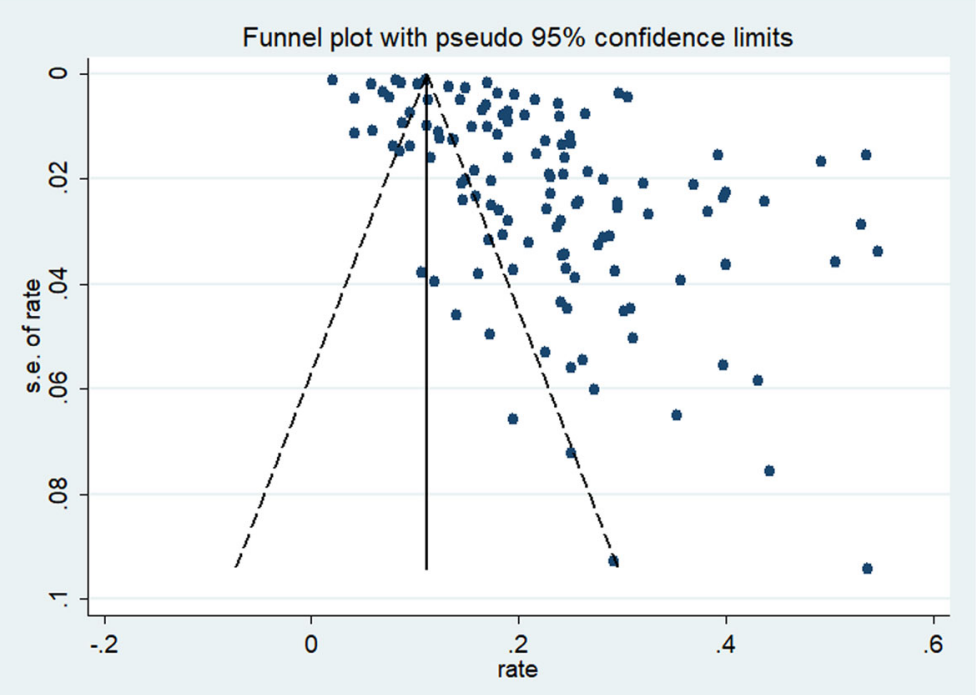

Fig. 3 Funnel plot for the incidence of survival to admission among OHCA patients who underwent CPR 


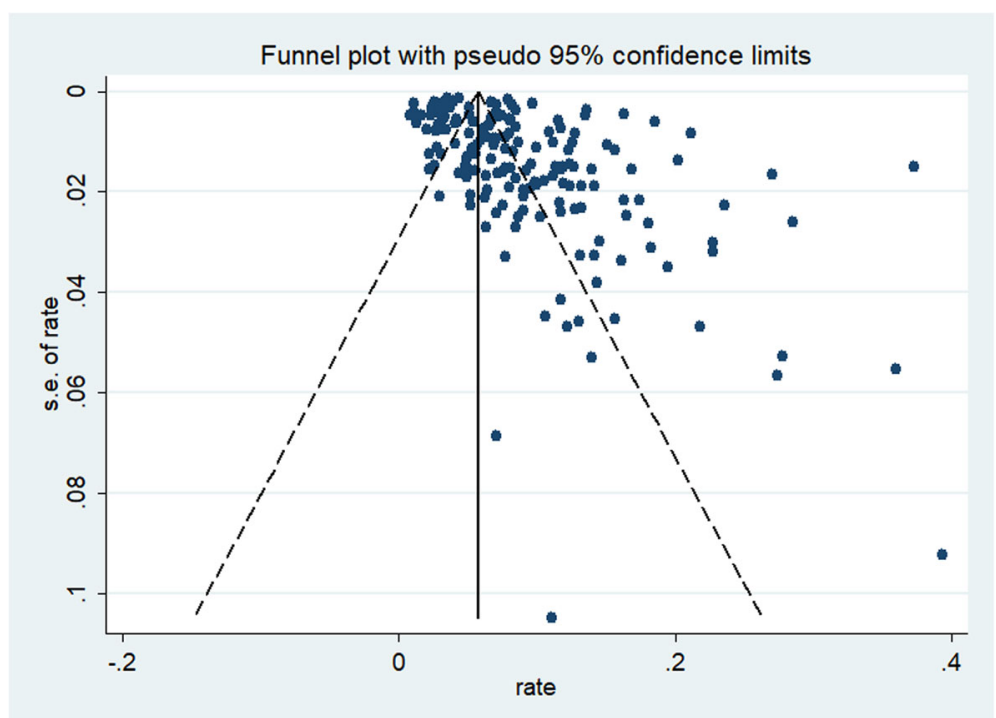

Fig. 4 Funnel plot for the incidence of survival to discharge among OHCA patients who underwent CPR

addition, our review performed more detailed subgroup analyses (stratified by sex, study location, study period, type of OHCA, type of CPR, and type of cardiac arrest witness) to test the robustness of the results and explore the potential heterogeneity.

Our subgroup analyses led to two valuable findings. First, much lower rates of ROSC, survival to admission, and survival to discharge were observed in Asian countries than in European counties. These observed differences may in part reflect the differences in first registered arrhythmia as VT/VF, witnessed collapse, bystander CPR, and early defibrillation in various countries $[4,24]$. These factors were significantly associated with the survival rates of OHCA patients [25-27]. Another explanation is that compared with North America and Europe, and the popularization of bystander CPR has been relatively delayed in Asia; thus, the quality of bystander CPR might be lower in Asia. In addition, a previous study showed that the thresholds of EMS protocols for initiating resuscitation are lower in Asian countries, [1] which was likely to contribute to the differences in the survival rates.

We also found much higher rates of survival to discharge, 1 month survival, and 1 year survival among OHCA patients who received bystander CPR, which was

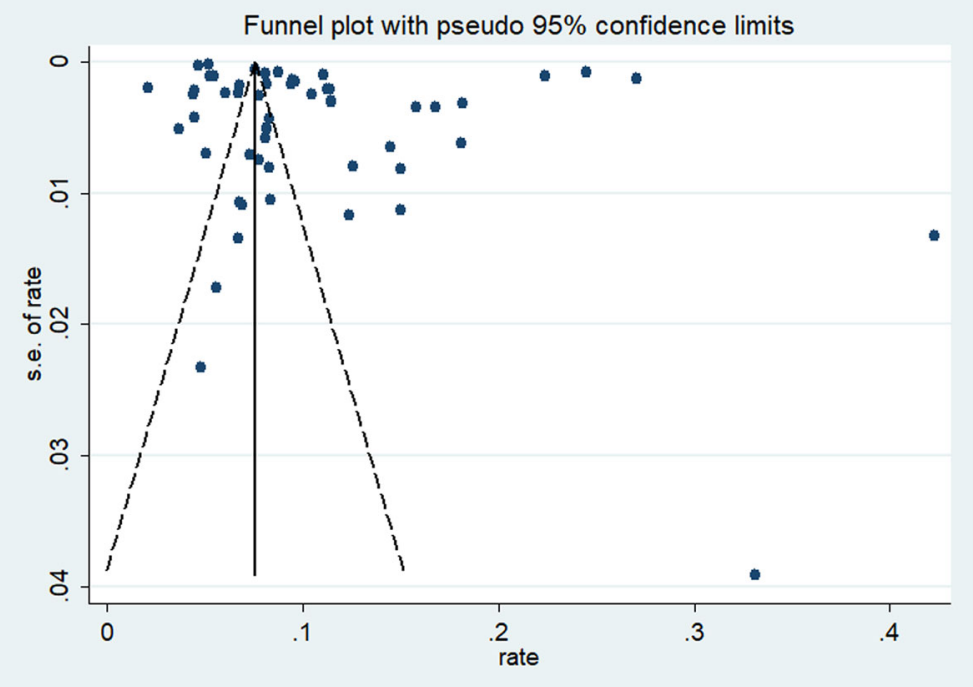

Fig. 5 Funnel plot for the 1 month survival rate among OHCA patients who underwent CPR 


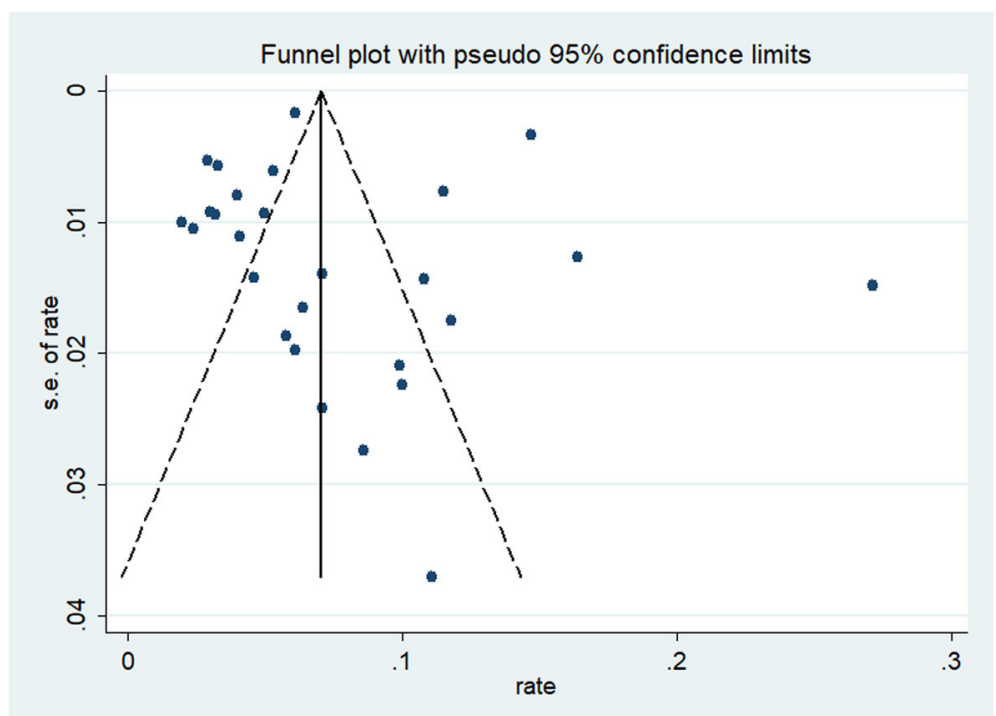

Fig. 6 Funnel plot for the 1 year survival rate among OHCA patients who underwent CPR

consistent with the findings of previous studies [26, 28-30]. This suggests that efforts, such as targeted CPR training to increase the bystander CPR rate, will have a substantial effect on improving the survival rates after OHCA [6,31]. Thus, facilitating bystander CPR training is an important and effective measure that governments worldwide can implement to improve the outcome of OHCA patients.

\section{Strengths and limitations}

The present study has several strengths. First, this is the first study to date investigating the survival of OHCA patients worldwide. Second, based on the subgroup analysis, we showed that the survival to discharge rate was much lower in developing countries than in developed counties, and the ROSC and survival to discharge rates were decreasing. Finally, as the incidence of OHCA is increasing in modern society, the results of our study can not only serve as baseline data for the global assessment of OHCA prevention interventions (evidence-based region-specific guideline updates of CPR for OHCA) but also provide a reference for international comparisons.

Potential limitations in this study need to be acknowledged. A high degree of heterogeneity was observed in this meta-analysis. The heterogeneity across studies may result from differences in the EMS system, research method, samples, provider and quality of CPR (e.g., bystander CPR, EMS CPR), and Utstein definition. However, the sensitivity analyses and consistent results from various subgroup analyses suggested that the estimates were relatively robust, and the heterogeneity can be overestimated when studies with large sample sizes are pooled. Second, only those studies published in English were included in this meta-analysis and studies in other languages were omitted. Third, the literature searches were carried out in three databases, which may be considered a source of bias.

\section{Suggestions for further research}

More effort should be put into future research. First, more studies should be included to explore the predictors of survival of OHCA and investigate the associations between survival after OHCA and the predictors (age, sex, location of cardiac arrest, response time, CPR by bystander or EMS-physician-guided CPR, AED utilization). This would help elucidate the reasons for improved survival and the underlying mechanisms. Second, investigating the quality of life and cognitive and functional changes in survivors after OHCA will be valuable. Finally, more studies validating the cost-effectiveness of bystander CPR training or AED utilization are warranted.

\section{Conclusion}

In conclusion, this meta-analysis suggests that the rates of survival to discharge, 1 month survival, and 1 year survival are increasing among OHCA patients who receive CPR globally. Relatively lower survival to discharge rates were observed in Asian countries. Higher rates of survival to discharge, 1-month survival, and 1-year survival were found among OHCA patients who had their cardiac arrest witnessed by EMS or a bystander and who received bystander CPR. 


\section{Supplementary information}

Supplementary information accompanies this paper at https://doi.org/10. 1186/s13054-020-2773-2

Additional file 1: Table S1. Characteristics of included studies. Supplementary references.

\section{Abbreviations}

AED: Automated external defibrillator; Cl: Confidence interval: CPR: Cardiopulmonary resuscitation; EMS: Emergency medical services; OHCA: Out-of-hospital cardiac arrests; ROSC: Return of spontaneous circulation

\section{Acknowledgements}

We thank all the authors of the studies included in our meta-analysis.

\section{Authors' contributions}

SJY, YG, and CZL conceived and designed the study. SJY, YG, NJ, YQC, QZ, and SC participated in the acquisition of data. $Y G$ and $N J$ analyzed the data. YG and YQC gave advice on methodology. SJY, YG, and HJ drafted the manuscript, and YG, NJ, RXW, YQC, QZ, and CZL revised the manuscript. All authors read and approved the final manuscript. CZL is the guarantors of this work and had full access to all the data in the study and takes responsibility for its integrity and the accuracy of the data analysis.

\section{Funding}

This study was funded by the Major Science and Technology Plan Project of Hainan Province (ZDKJ201804). The funder had no role in study design, data collection and analysis, decision to publish, or preparation of the manuscript.

\section{Availability of data and materials}

Data may be made available by contacting the corresponding author.

\section{Ethics approval and consent to participate}

Ethical approval is not required for this systematic review.

\section{Consent for publication}

Not applicable.

\section{Competing interests}

The authors declare that they have no competing interests.

\section{Author details}

'School of Public Health, Hainan Medical University, Haikou, Hainan, China. ${ }^{2}$ Key Laboratory of Emergency and Trauma of Ministry of Education, Hainan Medical University, Haikou, Hainan, China. ${ }^{3}$ Department of Social Medicine and Health Management, School of Public Health, Tongji Medical College, Huazhong University of Science and Technology, Wuhan, Hubei, China. ${ }^{4}$ Department of Emergency, Hainan Clinical Research Center for Acute and Critical Diseases, The Second Affiliated Hospital of Hainan Medical University, Haikou, Hainan, China. ${ }^{5}$ Emergency and Trauma College, Hainan Medical University, Haikou, Hainan, China. ${ }^{6}$ School of International Education, Hainan Medical University, Haikou, Hainan, China. ${ }^{7}$ Department of Emergency, the First Affiliated Hospital of Hainan Medical University, No.3 Xueyuan Road, Longhua Zone, Haikou 571199, China.

Received: 25 October 2019 Accepted: 11 February 2020

Published online: 22 February 2020

\section{References}

1. Berdowski J, Berg RA, Tijssen JG, Koster RW. Global incidences of out-ofhospital cardiac arrest and survival rates: systematic review of 67 prospective studies. Resuscitation. 2010;81(11):1479-87.

2. Xu F, Zhang Y, Chen Y. Cardiopulmonary resuscitation training in China: current situation and future development. JAMA Cardiol. 2017;2(5):469-70.

3. Rea TD, Eisenberg MS, Sinibaldi G, White RD. Incidence of EMS-treated out-of-hospital cardiac arrest in the United States. Resuscitation. 2004;63(1):17-24.

4. Shao F, Li CS, Liang LR, Li D, Ma SK. Outcome of out-of-hospital cardiac arrests in Beijing, China. Resuscitation. 2014;85(11):1411-7.
5. Kragholm K, Wissenberg M, Mortensen RN, Hansen SM, Malta Hansen C, Thorsteinsson K, Rajan S, Lippert F, Folke F, Gislason G, et al. Bystander efforts and 1-year outcomes in out-of-hospital cardiac arrest. N Engl J Med. 2017:376(18):1737-47.

6. Leong BS. Bystander CPR and survival. Singap Med J. 2011;52(8):573-5

7. Hupfl M, Selig HF, Nagele P. Chest-compression-only versus standard cardiopulmonary resuscitation: a meta-analysis. Lancet. 2010;376(9752): 1552-7.

8. Katarina B, Rosenqvist $M$, Johan $H$, Jacob $H$, Leif S. Survival is similar after standard treatment and chest compression only in out-of-hospital bystander cardiopulmonary resuscitation. Circulation. 2007;116(25):2908-12.

9. Sondergaard KB, Wissenberg M, Gerds TA, Rajan S, Karlsson L, Kragholm K, Pape M, Lippert FK, Gislason GH, Folke F, et al. Bystander cardiopulmonary resuscitation and long-term outcomes in out-of-hospital cardiac arrest according to location of arrest. Eur Heart J. 2019:40(3):309-18.

10. Kette F, Sbrojavacca R, Rellini G, Tosolini G, Capasso M, Arcidiacono D, Bernardi G, Frittitta P. Epidemiology and survival rate of out-of-hospital cardiac arrest in north-east Italy: The F.A.C.S. study. Friuli Venezia Giulia Cardiac Arrest Cooperative Study. Resuscitation. 1998:36(3):153-9.

11. Brison RJ, Davidson JR, Dreyer JF, Jones G, Maloney J, Munkley DP, O'Connor HM, Rowe BH. Cardiac arrest in Ontario: circumstances, community response, role of prehospital defibrillation and predictors of survival. CMAJ. 1992;147(2):191-9.

12. Hollenberg J, Bang A, Lindqvist J, Herlitz J, Nordlander R, Svensson L, Rosenqvist M. Difference in survival after out-of-hospital cardiac arrest between the two largest cities in Sweden: a matter of time? J Intern Med. 2005;257(3):247-54.

13. Ong ME, Shin SD, De Souza NN, Tanaka H, Nishiuchi T, Song KJ, Ko PC, Leong BS, Khunkhlai N, Naroo GY, et al. Outcomes for out-of-hospital cardiac arrests across 7 countries in Asia: the Pan Asian Resuscitation Outcomes Study (PAROS). Resuscitation. 2015;96:100-8.

14. Liberati A, Altman DG, Tetzlaff J, Mulrow C, Gotzsche PC, loannidis JP, Clarke M, Devereaux PJ, Kleijnen J, Moher D. The PRISMA statement for reporting systematic reviews and meta-analyses of studies that evaluate health care interventions: explanation and elaboration. J Clin Epidemiol. 2009:62(10):e1-34.

15. Stroup DF, Berlin JA, Morton SC, Olkin I, Williamson GD, Rennie D, Moher D, Becker BJ, Sipe TA, Thacker SB, et al. Meta-analysis of observational studies in epidemiology - a proposal for reporting. JAMA. 2000;283(15):2008-12.

16. Harris RJ, Bradburn MJ, Deeks JJ, Altman DG, Harbord RM, Sterne JAC. Metan: fixed- and random-effects meta-analysis. Stata J. 2008;8(1):3-28.

17. Higgins JPT, Thompson SG. Quantifying heterogeneity in a meta-analysis. Stat Med. 2002;21(11):1539-58.

18. Egger M, Davey Smith G, Schneider M, Minder C. Bias in meta-analysis detected by a simple, graphical test. BMJ. 1997;315(7109):629-34.

19. Sasson C, Rogers MA, Dahl J, Kellermann AL. Predictors of survival from outof-hospital cardiac arrest: a systematic review and meta-analysis. Circ Cardiovasc Qual Outcomes. 2010;3(1):63-81

20. van de Glind EM, van Munster BC, van de Wetering FT, van Delden JJ, Scholten RJ, Hooft L. Pre-arrest predictors of survival after resuscitation from out-of-hospital cardiac arrest in the elderly a systematic review. BMC Geriatr. 2013;13:68.

21. Ahn KO, Shin SD, Suh GJ, Cha WC, Song KJ, Kim SJ, Lee EJ, Ong ME. Epidemiology and outcomes from non-traumatic out-of-hospital cardiac arrest in Korea: a nationwide observational study. Resuscitation. 2010;81(8): 974-81.

22. Kim C, Becker L, Eisenberg MS. Out-of-hospital cardiac arrest in octogenarians and nonagenarians. Arch Intern Med. 2000;160(22):3439-43.

23. Swor RA, Jackson RE, Tintinalli JE, Pirrallo RG. Does advanced age matter in outcomes after out-of-hospital cardiac arrest in community-dwelling adults? Acad Emerg Med. 2014;7(7):762-8.

24. Eisenberg MS, Cummins RO, Larsen MP. Numerators, denominators, and survival rates: reporting survival from out-of-hospital cardiac arrest. Am J Emerg Med. 1991;9(6):544-6.

25. Gilmore CM, Rea TD, Becker $\amalg$, Eisenberg MS. Three-phase model of cardiac arrest: time-dependent benefit of bystander cardiopulmonary resuscitation. Am J Cardiol. 2006;98(4):497-9.

26. Song J, Guo W, Lu X, Kang X, Song Y, Gong D. The effect of bystander cardiopulmonary resuscitation on the survival of out-of-hospital cardiac arrests: a systematic review and meta-analysis. Scand J Trauma Resusc Emerg Med. 2018;26(1):86. 
27. Press AIN. CPR and rapid defibrillation increase survival rates in people with out-of-hospital cardiac arrests. Evid Based Healthcare Public Health. 2005;9(1):42-3.

28. Nordberg P, Hollenberg J, Herlitz J, Rosenqvist M, Svensson L. Aspects on the increase in bystander CPR in Sweden and its association with outcome. Resuscitation. 2009:80(3):329-33.

29. Hollenberg J, Herlitz J, Lindqvist J, Riva G, Bohm K, Rosenqvist M, Svensson L. Improved survival after out-of-hospital cardiac arrest is associated with an increase in proportion of emergency crew--witnessed cases and bystander cardiopulmonary resuscitation. Circulation. 2008;118(4):389-96.

30. Hasselqvist-Ax I, Riva G, Herlitz J, Rosenqvist M, Hollenberg J, Nordberg P, Ringh $\mathrm{M}$, Jonsson M, Axelsson C, Lindqvist J, et al. Early cardiopulmonary resuscitation in out-of-hospital cardiac arrest. N Engl J Med. 2015;372(24): 2307-15.

31. Koster RW, Baubin MA, Bossaert LL, Caballero A, Cassan P, Castren M, Granja C, Handley AJ, Monsieurs KG, Perkins GD, et al. European Resuscitation Council Guidelines for Resuscitation 2010 Section 2. Adult basic life support and use of automated external defibrillators. Resuscitation. 2010;81(10): 1277-92.

\section{Publisher's Note}

Springer Nature remains neutral with regard to jurisdictional claims in published maps and institutional affiliations.

Ready to submit your research? Choose BMC and benefit from:

- fast, convenient online submission

- thorough peer review by experienced researchers in your field

- rapid publication on acceptance

- support for research data, including large and complex data types

- gold Open Access which fosters wider collaboration and increased citations

- maximum visibility for your research: over $100 \mathrm{M}$ website views per year

At $\mathrm{BMC}$, research is always in progress.

Learn more biomedcentral.com/submissions 